\title{
AS CIDADES IMAGINÁRIAS DE ITALO CALVINO E GEORGES PEREC*
}

\author{
Dilma Castelo Branco Diniz ${ }^{\text {**: }}$
}

Resumo: Uma leitura comparativa dos romances As cidades invisiveis, de Italo Calvino $e$ W ou le souvenir d'enfance, de Georges Perec, com o objetivo de mostrar o emprego de duas formas diversas de narrar que manifestam uma nova ordem do discurso: a beterogeneidade dos jogos de linguagem.

Depois de um período passado em Roma no início dos anos 60, Italo Calvino vai morar até $1980 \mathrm{em}$ Paris, onde freqüenta os meios intelectuais da revista Tel Quel e do Oulipo - Ouvroir de Littérature Potentielle.

Desde a sua criação em 1960, o grupo Oulipo tinha como principal tarefa propor aos escritores a criação de novas estruturas: o escritor oulipien acrescenta às regras de linguagem comumente admitidas suas próprias regras ou contraintes, tomadas em geral de modelos científicos ou matemáticos. Ora, Calvino já possuía uma certa visão das relações da literatura com a ciência. Para ele, a ciência era não só uma fonte de inspiração, mas, sobretudo, modelo de rigor

\footnotetext{
${ }^{*}$ Recebido para publicação em abril de 2000.

**Professora Adjunta do Departamento de Letras Românicas da Faculdade de Letras da UFMG.
} 
e princípio de organização da matéria literária. Daí, o gosto e a preocupação com a numerologia: o amor pela simetria, a fascinação pelos números, cuja harmonia comanda a forma dos romances e até o tamanho e a distribuição dos capítulos. Essa atração de Calvino pelos números se lê claramente em várias de suas obras. Havia, portanto, afinidades estreitas entre Calvino e os membros do Oulipo, notadamente Raymond Queneau e Georges Perec. É em novembro de 1972 que Calvino participa, pela primeira vez e como "convidado de honra”, de uma reunião do grupo Oulipo. Uma sessão memorável, nos conta Marcel Benabou (BENABOU, 1990:41). Calvino falou longamente de um projeto, um romance (ou um conto, ele hesitava ainda) intitulado "Os mistérios da casa abominável": quatro personagens particularmente perversos cometeriam doze crimes e caberia ao leitor descobrir quem havia cometido o quê. Em seguida, Georges Perec expôs as grandes linhas de um projeto que iria mais tarde dar origem a... La vie mode d'emploi, romance que Calvino considera como "o último verdadeiro acontecimento na história do romance (CALVINO, 1990:135). Pouco tempo depois, em fevereiro de 1973, o Oulipo elege Italo Calvino como membre étranger, por unanimidade.

Marcel Benabou (BENABOU, 1990:42) afirma que o corpus das obras oulipiennes de Calvino comporta dois grupos: de um lado, trabalhos relativamente breves, mas com a marca de sua originalidade (como, por exemplo, o Piccolo Sillabario Illustrato, feito à imitação do Petit Abécédaire illustré, de Perec); do outro, obras de dimensões mais vastas e notáveis pela complexidade de sua estrutura, como os romances $O$ castelo dos destinos cruzados e Se um viajante numa noite de inverno.

Para se ter uma idéia mais precisa das relações de Calvino com o Oulipo, convém registrar aqui a nota do autor, acrescentada à edição francesa de Château des destins croisés, uma verdadeira profissão de fé: 
Je partageais avec l'Oulipo plusieurs idées et prédilections: l'importance des contraintes dans l'œuvre littéraire, l'application méticuleuse de règles du jeu très strictes, le recours aux procédés combinatoires, la création d'œuvres nouvelles en utilisant des matériaux préexistants. L'Oulipo n'admet que des opérations conduites avec rigueur; dans la confiance que la valeur poétique peut se dégager de structures extrêmement contraignantes. (apud BENABOU, 1990:44)

Essas breves considerações mostram bem a força dos laços que unem a obra de Italo Calvino e as pesquisas sobre a literatura potencial, às quais o Oulipo deve sua existência e seu nome.

Italo Calvino publica As cidades invisíveis em 1972 (ano de sua entrada no Oulipo) e Georges Perec lança $W$ ou le souvenir d'enfance em 1975. Calvino admirava Perec e o considerava "o mais inventivo dos participantes do Oulipo" (CALVINO, 1990:137). Por sua vez, Perec devia também admirar Calvino, já que possuíam um verdadeiro parentesco de espírito e de método. Como Perec escreveu W ou le souvenir d'enfance, no período de 1970 a 1974, pode-se presumir que houve uma troca de idéias entre os dois escritores a respeito desses livros.

Convém esclarecer que o que caracteriza mais profundamente talvez a nova literatura pós-moderna é uma volta ao saber narrativo. Mas como o narrador "inocente" e "omnisciente" não existe mais, essa volta se efetua por outros meios. A. Kibédi Varga, num artigo intitulado "Le récit postmoderne" afirma que:

Nous savons maintenant - Ricœur et McIntyre insistent là-dessus qu'on ne peut connaître le sujet que narrativisé, un personnage (réel ou romanesque) ne se présente jamais "tel qu'en lui-même", il se constitue à travers les innombrables histoires qu'il aura traversées. (...) Pour retrouver le sujet, pour lui rendre sa responsabilité morale et politique - ce que des philosopbes et des critiques aussi différents que Habermas, Lyotard, Rorty et Todorov réclament -, il faut donc lui rendre ses récits, lui réinventer ses bistoires (toujours au pluriel). (VARGA, 1990:17) 
Nesses tempos pós-modernos, esse esforço parece se fazer através da heterogeneidade dos jogos de linguagem. A leitura comparativa de $A s$ cidades invisíveis, de Calvino e $W$ ou le souvenir d'enfance, de Perec, que aqui se propõe, procura mostrar como esses dois autores adotam duas formas diversas de manifestar essa nova ordem do discurso.

\section{a) As novas estruturas narrativas}

O primeiro ponto de encontro entre esses dois livros está em suas respectivas estruturas.

A estrutura de Woule souvenir d'enfance, de Geerges Perec, é a de um paralelo, que surge em diversos níveis e que já aparece no título. A princípio, há nesse livro dois textos simplesmente alternados que parecem ser dois relatos que não têm nada em comum, mas eles estão inextricavelmente ligados, como se nenhum deles pudesse existir sozinho, como se somente de seu encontro nascesse uma luz que ilumina um e outro: algo que não está dito completamente em nenhum deles e que só é revelado nessa frágil intersecção. Uma intersecção que nos lembra "a ponte sobre o vazio", de que nos fala Calvino. "Talvez seja a minha narrativa que forma uma ponte sobre o vazio"(CALVINO, s.d.:79); ou ainda o comentário de Kublai Khan, quando Marco Polo, recém-chegado e ignorando totalmente as línguas do oriente, se exprimia mostrando objetos de sua mala: o mais valioso em todos os fatos e notícias referidos por seu informante era o "espaço que restava em torno deles, um vazio não preenchido por palavras"

Um dos textos, W, pertence somente ao imaginário: trata-se de um romance de aventuras, a reconstituição arbitrária, mas minuciosa de um fantasma infantil (fantasma no sentido psicanalítico),

\footnotetext{
'CALVINO, As cidades invisíveis (1990:41). As citações desse texto serão indicadas apenas por (CI), seguido da paginação.
} 
que evoca uma cidade regida pelo ideal olímpico. O outro texto é auto-biográfico: a narrativa fragmentária de uma vida de criança durante a $2^{a}$ Guerra Mundial, na França. É uma narrativa de poucos acontecimentos e de lembranças, feita de fragmentos esparsos, ausências, esquecimentos, dúvidas, hipóteses e pequenas anedotas.

É curioso observar também que a história fantasmática ocupa os capítulos de número ímpar e o relato autobiográfico os de número par. Do ponto de vista gráfico, eles também se distinguem: os capítulos ímpares vêm em itálico e os pares em letra comum.

O livro começa como uma narrativa de aventuras que tem algo de grandioso e de suspeito ao mesmo tempo. Isso porque ele começa a contar uma história e, de repente, se lança numa outra: nessa ruptura, nessa quebra do fio narrativo, que suspende a narrativa não se sabe em torno de que expectativa se inicia o lugar de onde saiu esse livro, essas reticências, esses pontos suspensos aos quais estão presos os fios rompidos da infância e a trama da escrita.

As cidades invisiveis, de Calvino, apresentam também uma estrutura dúplice, semelhante a essa: de um lado, temos o diálogo entre Marco Polo e Kublai Khan, grafados em itálico; do outro, as descrições das cidades em escrita normal. Mas, entre os dois livros, há uma diferença fundamental na estrutura. Se Perec constrói a estrutura de seu livro em forma de paralelo, Calvino consegue construir uma "estrutura facetada". É o próprio escritor que explica que "cada texto curto está próximo dos outros numa sucessão que não implica uma conseqüencialidade ou uma hierarquia, mas uma rede dentro da qual se podem traçar múltiplos percursos e extrair conclusões multíplices e ramificadas."(CALVINO, 1990:86)

Dessa maneira, As cidades invisiveis adquirem um sentido que não é nem fixo, nem definido, nem endurecido numa imobilidade mineral, mas tão vivo quanto um organismo. Mas Calvino ainda explica que "cada conceito e cada valor se apresenta dúplice", em As cidades invisíveis, "até mesmo a exatidão"(CALVINO, 1990:86- 
88). E que sua busca da exatidão se bifurca em duas direções, que coincidem com caminhos diferentes de seu texto. De um lado, sua escrita procura reduzir os eventuais acontecimentos a esquemas abstratos que permitam o cálculo e a demonstração de teoremas; do outro, ela se esforça para conseguir representar, com a maior precisão possível, o aspecto sensível das coisas.

O livro de Perec se inicia com a hesitação do narrador diante do relato de suas experiências: "J'ai longtemps bésité avant d'entreprendre le récit de mon voyage à $W^{.2}$ O narrador afirma que, por muito tempo, quis guardar segredo sobre o que viu e que, às vezes, tudo aquilo the parecia ter sido um inesquecível pesadelo. Dá em seguida algumas indicações sobre sua vida, indicações muiito imprecisas: nasceu no dia 25 de junho de $19 \ldots$, em R., não longe de A. Mais tarde, entra para o exército, mas não se adaptando bem à vida militar, deserta pouco tempo depois. Ajudado por um grupo de pacifistas, consegue uma identidade falsa. Assim, aos olhos do leitor, esse relato se manifesta suspeito. Só mais adiante, é que vamos saber o nome falso do narrador - Gaspard Winckler - nome que pertencia, na verdade, a um menino de oito anos, que tinha morrido num naufrágio perto da Terra do Fogo. E seu corpo nunca foi encontrado, apesar de terem sido intensas as buscas!...

A primeira parte do livro termina com a pergunta do falso Gaspard: teria ele mais chance que os outros de encontrar aquele menino? Fica claro para o leitor o significado daquele relato: tratase de uma busca de identidade.

A narrativa autobiográfica, por sua vez, também se apresenta misteriosa, mas um fato se destaca: a infância do narrador estava ligada à guerra.

\footnotetext{
${ }^{2}$ PEREC, $W$ ou le souvenir d'enfance (1990:9). As citações desse texto serão indicadas por (W), seguido da paginação.
} 
Je n'ai pas de souvenirs d'enfance: je posais cette affirmation avec assurance, avec presque une sorte de défi. L'on avait pas à m'interroger sur cette question (...) J'en étais dispensé: une autre bistoire, la Grande, l'Histoire avec sa grande bacbe, avait déjà répondu à ma place: la guerre, les camps. (W, p.89)

O narrador conta ainda que foi com treze anos de idade que ele inventou, contou e desenhou uma história. Mais tarde, ele a esqueceu e só voltou a se lembrar dela, certa noite em Veneza. A história se chamava $W$ e era, de certa maneira, senão a história, ao menos uma história de sua infância. Essa história era a vida de uma sociedade exclusivamente preocupada com o esporte, numa pequena ilha da Terra do Fogo.

Pouco a pouco, o leitor começa a perceber os vínculos existentes entre os dois personagens: a letra inicial de Gaspard é a mesma de Georges; o nome da mãe de Perec era Cyrla Schulevitz, mas chamavamna de Cécile e Caecilia era a mãe de Gaspard e assim por diante.

A segunda parte do livro começa com a descrição da ilha W: "Il y aurait, là-bas, à l'autre bout du monde, une île. Elle s'appelle W."(W, p.89) O emprego do conditionnel já é um dado lingüístico que expressa a incerteza (ou suposição) dos fatos acontecidos no passado. A ilha, no outro lado do mundo, acha-se rodeada de recifes, com falésias abruptas e nenhum desembarcadouro natural. Nesse espaço isolado, vive uma sociedade fechada em que o esporte é rei, uma nação de atletas em que o esporte e a vida se confundem num mesmo e magnífico esforço.

Paralelamente, o narrador autobiográfico revela que a época de W - período compreendido entre seus onze e quinze anos de idade - foi uma época caracterizada pela ausência de pontos de referência. De família judia, Georges havia saído de Paris num comboio da Cruz Vermelha que levava feridos para a zona livre. Por isso, ele tinha o braço na tipóia, apesar de não estar ferido. Foi sua mãe que o levou à Gare de Lyon e lhe comprou uma revista com o 
retrato de Carlitos na capa. Foi a última vez que viu a mãe, deportada, mais tarde, seguindo para Auschwitz. ${ }^{3}$

Vivendo nos arredores de Grenoble, ele costumava visitar um velho carpinteiro que serrava madeira num cavalete, cujos pés formavam um $X$, figura que se chama "Cruz de Santo André". A citação de Santo André lembra ao leitor o seu martírio e também o remete a um dado anterior do texto - quando Georges fala de seu pai que se chamava Icek, mas que todos chamavam de Isie (ou Isy), comenta em seguida: "Je suis le seul à avoir cru, pendant de très nombreuses années, qu'il s'appelait André." (W, p.51)

Continuando a sua história, o narrador afirma que o signo $\mathrm{X}$ - signo contraditório da ablação (em neurofisiologia) e da multiplicação, da colocação em ordem (eixo dos X) e do desconhecido matemático - foi o ponto de partida de uma "geometria fantasmática", cujo V desdobrado constituía a figura de base e cujos entrelaçamentos múltiplos traçavam os símbolos mais importantes da história de sua infância. Assim, dois $V$ juntos pelo vértice formam um $\mathrm{X}$; prolongando os braços do $\mathrm{X}$ com segmentos iguais e perpendiculares, obtém-se uma cruz gamada (5) que pode ser facilmente decomposta em (SS); a superposição de dois V invertidos dá a figura $(X X)$ da qual basta reunir horizontalmente os braços para se obter a estrela judaica (\&). É nessa mesma perspectiva que ele se lembra do fato de Charlie Chaplin, em O grande ditador, ter trocado a suástica por dois X entrecruzados (X).(W, p.106)

Torna-se relevante observar que todos esses símbolos se situam num mesmo plano, mesmo que sejam considerados opostos, como é o caso da suástica e da estrela-de-davi.

Outro traço marcante dessa narrativa autobiográfica é "a cicatriz". Vivendo perto dos Alpes, Georges esquiava freqüentemente com os

\footnotetext{
${ }^{3}$ A questão judaica, presente na narrativa autobiográfica, não será examinada no espaço
limitado deste trabalho.
} 
colegas de colégio. Certo dia, ao guardar os esquis, um deles escapou das mãos de Georges e passou raspando pelo rosto do menino a seu lado que, furioso, bateu o bastão em seu rosto, cortando-lhe o lábio superior. O narrador confessa que, por razões mal elucidadas, a cicatriz que resultou dessa agressão parece ter tido para ele uma importância capital: foi essa cicatriz que o fez preferir a todos os quadros do Louvre o Portrait d'un bomme, chamado Le Condottiere d'Antonello de Messine, que se tornou a figura central do primeiro romance que conseguiu escrever. Esse romance chamava-se Gaspard pas mort, depois Le Condottiere. Em versão final, o herói, Gaspar Winckler é um falsário de gênio. O narrador continua afirmando que Le Condottiere e sua cicatriz tiveram também um papel preponderante em Un bomme qui dort (o terceiro romance de Perec):"(...) le portrait incroyablement énergique d'un bomme de la Renaissance, avec une toute petite cicatrice au-dessus de la lèvre supérieure, à gaucbe, c'est-à-dire à gauche pour lui, à droite pour toi (...)"(W, p.142).

Até no filme, feito a partir de Un bomme qui dort, o ator Jacques Spiesser tem uma cicatriz no lábio superior. O narrador revela: "c'était un simple basard, mais il fut, pour moi, secrètement déterminant"(W, p.143). A cicatriz torna-se o traço que une ainda mais Gaspar Winckler e Georges Perec.

Gaspard Winckler será ainda um personagem importante de La vie mode d'emploi (1978). Ele é um fabricante de puzzles e uma metáfora do autor já que no início do livro, no Préambule, o autor transcreve ipsis litteris a primeira parte do capítulo intitulado Winckler 2 sobre a arte do puzzle, em que o autor seria o faiseur de puzzles e o leitor o poseur de puzzles.(PEREC, 1978:18)

$\mathrm{Na}$ verdade, a estrutura de Wou le souvenir d'enfance apresenta um aspecto lúdico, característico de um jogo de encaixe, em que cabe ao leitor unir as peças separadas, construídas pelo autor com essa finalidade. 


\section{b) A valorização da subjetividade}

O espaço social fechado da cidade W, a sociedade comunitária e triunfante que vive numa ilha ao sul do Equador são elementos que nos remetem à Utopia de Thomas Morus. Mas, ao longo da narrativa, essa idéia utópica vai sendo desconstruída. As injustiças do sistema W vão aparecendo pouco a pouco e é, no fim do livro, que aparece para o leitor o sentido da narrativa: a cidade "W" é, na verdade, um campo de concentração. O autor usa a técnica da dissimulação: desde o início, o leitor encontra-se desorientado; no meio do percurso, a narrativa toma aspectos inquietantes e inesperados e é só depois de terminada a leitura que o leitor está apto a conferir um sentido unificador aos acontecimentos apresentados pelo texto.

O universo concentracionário que surge no final do livro ligase de imediato a Auschwitz, campo citado anteriormente, onde morreu a mãe do narrador/autor. Lembramo-nos do comentário de Adorno - não se pode mais filosofar depois de Auschwitz como antes, e do de Lyotard - Auschwitz é o fim da modernidade. A História "progressista" atinge aí o totalitarismo, perdendo assim toda a sua legitimidade (Cf. LYOTARD, 1986:132): um futuro que remete ao passado.

Mas se o livro de Perec traz, como mensagem, a descrença na utopia, ele não deixa de abrir uma brecha para a esperança. A recusa do passado se completa com uma visão do futuro. O último parágrafo constitui uma crítica que é ao mesmo tempo uma advertência:

J'ai oublié les raisons qui, à douze ans, m'ont fait choisir la Terre de Feu pour y installer W : les fascistes de Pinochet se sont chargés de donner à mon fantasme une ultime résonance:plusieurs îlots de la Terre de Feu sont aujourd'bui des camps de déportation. (W, p.220)

É interessante constatar que o fim de As cidades invisíveis se assemelha ao fim de $W$ ou le souvenir d'enfance. Calvino também não crê na utopia, mas deixa transparecer, no final do livro, a esperança: 
Existem duas maneiras de não sofrer. A primeira é fácil para a maioria das pessoas: aceitar o inferno e tornar-se parte deste até o ponto de deixar de percebê-lo. A segunda é arriscada e exige atenção e aprendizagem contínuas: tentar saber reconhecer quem e o que, no meio do inferno, não é inferno, e preservá-lo, e abrir espaço. (CI, p.150)

Terminada a leitura de Wou le souvenir d'enfance, compreendese melhor o significado das epígrafes que introduzem cada parte do texto:

Première partie — "Cette brume insensée où s'agitent des ombres, comment pourrais-je l'éclaircir?" (W, p.87)

Deuxième partie - "Cette brume insensée où s'agitent des ombres, - est-ce donc là mon avenir?" (W, p.87)

Esses versos de Queneau nos remetem a um trecho do diálogo entre Marco Polo e Khan: “- Você viaja para reviver o seu passado? - era a esta altura, a pergunta do Khan, que também podia ser formulada da seguinte maneira: - Você viaja para reencontrar o seu futuro?" (CI, p.29)

Desconstruindo as dicotomias e apagando suas fronteiras, a narrativa pós-moderna coopera no sentido de elaborar uma estética generalizada, em que a sensibilidade contemporânea vê na arte um meio de estender nossa experiência de vida. É nesse sentido que devemos considerar o símbolo da "cidade", usado nesses livros, tanto por Perec quanto por Calvino. Lembramo-nos das reflexões de Félix Guattari (GUATTARI, 1990) sobre a "subjetividade urbana" do homem moderno. O ser humano contemporâneo é fundamentalmente desterritorializado, escreve o filósofo, seus territórios etnológicos originários - corpo, clã, aldeia, culto - não estão mais dispostos num ponto preciso do planeta, mas se incrustam, no essencial, em

'Os grifos são meus. 
universos incorporais. A subjetividade entrou no reino de um nomadismo generalizado onde tudo circula: as músicas, os anúncios publicitários, os turistas, os chips de informática, as filiais industriais. Mas, embora tudo circule, paradoxalmente, tudo parece estar fixo, porque, nos espaços padronizados, tudo se torna intermutável, equivalente. Como, atualmente, é impossível aos homens reatar-se às suas terrras natais, o que thes resta é reconstituir uma relação particular com o cosmos e com a vida, é se recompor em sua singularidade individual e coletiva. Trata-se, afirma Guattari, da restauração de uma "cidade subjetiva", que opera o engajamento dos niveis mais individuais da pessoa com os mais coletivos. Convém ainda lembrar que, para Guattari, a subjetividade é "polifônica"(GUATTARI, 1992:11): "Eu é um outro, uma multiplicidade de outros, encarnado no cruzamento de componentes de enunciações parciais extravasando por todos os lados a identidade individuada." (GUATTARI, 1992:105)

Compreende-se assim que o símbolo da cidade se reveste de uma riqueza extraordinária. Talvez seja por isso que Calvino declarou que o símbolo que the permitiu maiores possibilidades de exprimir" "a tensão entre racionalidade geométrica e emaranhado das existências humanas"(CALVINO, 1990:85) foi o da cidade.

\section{c) $\mathbb{A}$ ieescrita}

Ao retomar O livro das maravilhas de Marco Polo, Italo Calvino utiliza o processo da reescrita em As cidades invisíveis. Empregando personagens históricos como Marco Polo e Kublai Khan em sua obra, o autor insiste no caráter necessariamente ficcional de toda narração histórica e sobre a parte incontornável da literatura na historiografia. A reescrita só pode se referir, naturalmente, a gêneros narrativos conhecidos e extensamente codificados. Ela se diferencia da paródia propriamente dita, na medida em que sua atitude em relação ao pré-texto é alusiva e lúdica. O romance 
do futuro se transforma em reescrita de modelos retrospectivos: as ficções de Calvino se inscrevem então numa perspectiva intertextual que as legitima e que faz de sua leitura uma viagem através da literatura.

As cidades de Calvino pertencem a uma cartografia imaginária. Elas superpõem os tempos e os espaços num labirinto, onde se procura não um ponto de chegada, mas uma infinidade de percursos. Existe, ainda, em $A s$ cidades invisiveis, a idéia de um desafio que traduz uma vontade hermenêutica, que se revela na ordem mesma do livro, em termos de meta-discurso. Se os percursos seguidos por Marco Polo para chegar às cidades invisíveis, que a descrição mostrará, definem um espaço-tempo descontínuo, lacunar, é porque, nesse caminho, num espaço sem coordenadas, está, simbolicamente, o único caminho possível. Trata-se, realmente, do símbolismo dos percursos romanescos. Talvez seja por isso que as cidades de Calvino têm nomes femininos: são cidades ligadas à mãe, à "terra-mãe", à fundação da narrativa. Num diálogo com o Khan, Marco Polo confessa: "Todas as vezes que descrevo uma cidade digo algo a respeito de Veneza"(CI, p.82). Curiosamente, no livro de Perec, a cidade de Veneza está também ligada à narrativa. É em Veneza que o narrador autobiográfico se lembra da história fantasmática: "(..) un soir à Venise, je me souvins tout à coup que cette bistoire s'appelait W".(W, p.14); é ainda em Veneza que Gaspard Winckler decide escrever sobre a cidade "W".(W, p.10) O escritor cria seu antecessor: Calvino, leitor de Marco Polo; Perec, leitor de Calvino.

"La littérature est anabase, cheminement vers l'intérieur"(DAROS, 1990:32) - Calvino tinha escrito, em 1964, um prefácio à Anabase, de Xenofonte, que é revelador desse tema. Nessa perspectiva, não é de se admirar que a intertextualidade de Calvino se volte aos "modelos do passado". Assim, os diálogos entre Marco Polo e o Khan refletiriam os primeiros diálogos de nossa cultura: os de Platão. 
Percebemos, ao longo desses dois textos, $W$ ou le souvenir d'enfance e As cidades invisíveis, um triplo retorno - do sujeito, da ética e do saber narrativo - um retorno que se efetua no desejo, e não, sobre a base de nenhuma "grande narrativa de legitimação"(LYOTARD, 1983). "Os símbolos formam uma língua, mas não aquela que você imagina conhecer. (...) Não há linguagem sem engano." (CI, p.48)

Assim, o homem que hoje deseja se reconciliar com o mundo narrável, só pode fazê-lo através de suas próprias histórias. A reescrita e a dissimulação são duas formas de narrar que encontramos em $A s$ cidades invisíveis e em $W$ ou le souvenir d'enfance, respectivamente. Entretanto, convém esclarecer que a distinção entre reescrita e dissimulação concerne somente à forma de narrar. O sentido do texto já se encontra minado, nos dois casos, por uma ruptura que instaura uma nova ordem do discurso: a ordem do heterogêneo.

Résumé : Une lecture comparative des romans As cidades invisiveis, d'Italo Calvino et $\mathrm{W}$ ou le souvenir d'enfance, de Georges Perec, dans le but de montrer l'emploi de deux formes narratives diverses qui manifestent un nouvel ordre du discours: l'bétérogénéité des jeux de langage.

\section{Referências bibliográficas}

BENABOU, Marcel. Si par une nuit d'hiver un oulipien. Magazine Littéraire. Paris, v. 274, p. 41-44. fév. 1990.

CALVINO,Italo. Seis propostas para o próximo milênio.São Paulo:Companhia das Letras, 1990.

CALVINO, Italo. As cidades invisíveis. Trad. Diogo Mainardi. São Paulo: Companhia das Letras, 1990. 
CALVINO, Italo. Se um viajante numa noite de inverno. São Paulo: Círculo do Livro, s.d..

DAROS, Philippe. Les parcours d'écriture. Magazine Littéraire. Paris, v. 274, p. 30-33. fév. 1990.

GUATTARI, Félix. Restauração da cidade subjetiva. Jornal do Brasil, Rio de Janeiro, 29 de julho de 1990.

GUATTARI, Félix. Caosmose, um novo paradigma estético.Trad. Ana Lúcia de Oliveira e Lúcia C. Leão. Rio de Janeiro: Editora 34, 1992.

LYOTARD, Jean-François, Le différend. Paris: Editions de Minuit, 1986.

LYOTARD, Jean-François. La condition postmoderne. Paris: Les Editions Minuit, 1983.

PEREC, Georges. W ou le souvenir d'enfance. Paris: Denöel, 1990.

PEREC, Georges. La vie mode d'emploi. Paris: Hachette, 1978.

VARGA,A. Kibédi. Le récit postmoderne. Littérature.Paris, n. 77, p. 3-23, fév. 1990. 